\title{
Modelling the Production Planning in the case of Production and Asset Constraint Considering the Rejected and Recycled Product keeping Centres (Case Study: Water Pump Producer)
}

\author{
Masoud Seidi ${ }^{1,}$ - Mehdi Jamshidnia² \\ ${ }^{1}$ Assistant professor, Ilam University, Faculty of Engineering, Ilam, Iran \\ ${ }^{2}$ Master Student, Industrial Engineering, Persian Golf International University, Abadan, Iran
}

\begin{abstract}
This study aims to provide a general modelling for production planning and the supply chain control in a large scale, in which the asset constraint and places for recycling and junking are added to the issues of production and capacity limitations of the company. Accordingly this study includes the optimization of production process besides the supply chain control proposes and the feasibility of recycle centres in order to decrease the production expense and having more profitability, which finally lead to the customer satisfaction and production system efficiency. The objective function of the model includes the optimization of the expenses on some matters such as establishment of recycling centres, production, accumulation centres, recycling and junking, warehousing, orders and transportations expenses. To estimate the model it is applied on a company which produces water pumps with different powers. The results revealed that the total expense of the system was increased in a period of 12 months related to the expense on establishment of recycle centres, while in a period of 48 month not only the money put into the recycle centres was returned, but also the production cost of each pump was totally decreased for 11 unites. This decline in the total expenses was due to the balance made by using the recycled materials instead of the new raw materials. To sum up, the more factories in which recycled materials are used, the less expenditure is predicted for system in all.
\end{abstract}

Key Words: Production Planning, Supply Chain, Production Capacity, Asset Constraint, the Rejected Product, Recycling and Accumulation centres. 


\section{Introduction}

$\mathrm{N}$ owadays determining the market's real orders and the probable demands of the future on the one hand, and on the other tailoring these demands with the theoretical and practical capacity of the producing companies became one of the most important and the most difficult issues in the production planning. In fact, manufacturing industrial product strategies are not limited to the production and marketing policies, besides, the guidelines in the field of production capacity constraints which are related to the limitations in working shifts, manpower, machines power, etc. could have effective impact on the policies of the company management especially in the time of peak of marketing and orders fluctuation (1). In this situation, one of the important policies considered in the production planning is to make a direct effective relationship between capacities of the company and probable demands of the market in order to make the maximum benefit and the least detriment. There are different factors to study and determine the relation between the company's capacity constraints and the probable demands of the market in the production planning system. In this case, introducing a method to determine the cumulate size and the way of making orders in production planning with the production capacity limitations in unauthorized shortcoming is considered because there will be notions of categorizing the cases of determining the cumulate size according to the type of the demand and existence or absence of the demand limitation.

In recent years considerable attention from researchers and industry is paid to production planning, because of the ability of these models to control production costs and inventory. Considering the importance of the discussion and production planning role in moderating the relationship between the limited production capacity of the company and the potential market demand, different models and methods to communicate between the two variables are considered. [2]

Based on the theory of constraints in production capacity and market demand, production planning systems try to explain the different models to cover this subject and the possible gaps. In an industrial organization, the authorities should know and determine the needs to each of the factors of production levels in the next year and the years after and announce them to the parts of requirements of logistics, personnel, training and other concerned units in the industry to supply them [3].

Using the design process and the layout of production lines is one of the most important issues that have a significant influence on production planning. Design production and assembly lines for product installation, the principles that should be considered would include scheduling, coordination, and balance the various stages of the production process. As a result the layout design process, determine the best location for business centres. Our business centres in the layout process are related to handling and transport of materials and labour, and they should be located in places that are close to each other in order to lessen displacement costs. In this study the researchers seek production planning by reviewing company's production capacity constraints and the investment restrictions.

Planning basically means forecasting a certain look about the what, how, in what time and by what people we should reach a goal. Planned production in the proper sense, that is expected to provide timely and factors needed to produce the desired product and, in fact determines the quantity and quality of the products which have been set as the target.(4)

To produce any commodity each system needs three main factors of "manpower", "raw materials" and "machinery and equipment" 
that have been known as the "factors of production". During the manufacturing process, raw materials become as known commodities to be marketed by using the necessary equipment and labour. To prevent any interruptions and irregularities in work and to be clear and logical in production planning system, it is necessary to define different periods of short-term (one year to three years) and long term (three years) for any production factors.

There are main challenges in designing a successful production planning system: Optimized production, optimized time, constraints on production and demand. Although the successful production planning system is designed according to the organization's strategies, including production capacity and marketing systems, and industry competitive landscape, inhibition of uncertainty is mainly among the most important challenges. Fluctuations in demand, concerns of the processing, and procurement chain are three main sources of uncertainty in the chain, and the role of demand fluctuation is often prominent in this regard. To control the unforeseen fluctuations in the amount or mixed of the demand there are three conventional strategies: inventory, lead time and capacity.

Production planning is the best use of resources to meet the production targets during a specified period called the planning horizon. One of the most common ways to determine the amount of production planning and production period is known as sizing production. One of the essential outputs and widely used system of production planning is program production. The plane determines and specifies which products, to what extent and in which period must be produced. In determining this application, models are used to determine the size category. In programming production systems due to the potential for production according to customer orders and assembly systems in accordance with the order, the importance of this type of planning has increased. The case of a random demand variable, the issue is very complex and little works have been done in this area.
Works primarily have done on possible issues without capacity constraints.

Supply chain management approach is a new approach that has been applied in recent years on the management of operations and production. In general, the supply chain is a network of facilities and distribution centers which is occupied in supplying raw materials, converting these materials into finished products, and distributing of the final products. There are supply chains in manufacturing and service organizations, although influenced by various factors, the complexity of the chain may be changed from industry to industry and company to company [5]. In general, the supply chain is a network of organizations which associates upstream to downstream, and involves process and activities for providing goods and services to the customer, so it gives the production a value [6].

\section{Theory and literature}

In general the traditional producers of goods and items deny any responsibilities for distributed and used products after they get to the customers. But today the volume of used products has led to considerable environmental damage, and everyone including consumers and the authorities are concerned about their environment with great concern, and the process continues to pursue improvements to the environment. Collection and recycling system is a small but important area of today's supply chain, allowing company managers to back rejected goods and raw materials to suppliers, maintain the continuity and coordinate the activities of production and distribution, prevent stopping operations due to the lack of available stock, adopt policies for the imported goods, and finally adopt systems and procedures to reduce total expenses.

Among the most crucial terms of recycling and reuse of goods produced in the reverse supply chain is separating usable items from unusable ones. Usable items can be utilized as an alternative for ordered parts, because a lot of uncertainty and discontent is caused by the direct relationship between the returned products, with time, quality and quantity of 
goods. Replacing the usable items of the returned goods, leads to cost savings in addition to consumer satisfaction in different aspects, and this can be gained with establishing a strong planning system in production. For better differentiation of returned items in terms of being usable or not in the supply chain there should be a warehouse for usable returned and also another storage provided for unusable returned items. Then according to the product type and the returned items and related to the grading we should place different stages of continuous improvement in the supply chain so it can come back to the supply chain if possible. Implementation and supply chain management needs an independent company with huge investment. So every step of the supply chain with regard to the system of collecting and recycling requires a significant amount of capital to collect waste and the remove the final product.

On the subjects of production planning with limited capacity of company, potential demand market, and limited investment there are studies conducted within and outside the country, some of these studies will be discussed. Production planning with potential demand and production resource constraints by combining the concept of service level and low cost, determine the category in case of multi-product and in different periods are among the most critical activities in production activities at each company. Using the concept of service levels and combined deficiency cost can increase the company's flexibility. Combining the deficiency cost and level of service in a company considering possible demand and the limited productive resources are to specific values. Due to the companies' extension and their need to have a reliable program and variety o customer demands, we need a model with high confidence that determine the rate of production of each product in each period due to the different expenses, and limited capacity and service level according to management view. So using the modeling and solving it, we have obtained the optimal values with minimal cost, and finally came to the conclusion that the deficiency cost and service level management have a significant role in production and determining the optimal production of the company [7]. Offering an innovative method to determine the ordering in single-stage production planning considering the production capacity constraint, in this paper with review of the literature in this area, a new initiative to solve the proposed model, an innovative method has been introduced to solve the model. Introducing the innovative method the initial solution for the model is obtained without the limitation of capacity by method of WagnerWhitin, and we tried while satisfying the requirement of reasonableness of the questions as possible, the total cost is reduced. Finally while coding the innovative proposed method and dynamic planning method with assuming normal distribution of demand, two methods are compared at the time of calculation that show innovative proposed method takes less time than the dynamic planning method [8]. In some manufacturing companies which are producing a particular product, sometimes you may reach customer demand to such an extent that demand is greater than the rate of production, in such a situation the rate of importation of goods into the warehouse is less than the rate of withdrawal of the products. So they will confront short supply at the rest of the planning period the high costs including deficiency cost in the system, the cost of losing customers will be imposed to the company. The company is forced to deal with such problems in the first period of planning to buy some of the goods to raise the level of warehouse not to meet exiting goods from the warehouse. A model is introduced for determining the optimum amount of production and the purchase of the company with the aim of minimizing the costs of the existing system, at first the model is checked in single item situation. Since the model along with the purchase of multi-production has more applications, this model is made in the case of multi-product development and ultimately software is used to fix the model. (9)

\section{The proposed model}


Most studies in the field of supply chain are designed to choose suppliers in a single product or multiple products and in recent years because of the complexity of the model and mathematical calculations, few studies have been done in the field of supply chain regard to collection centers and recycling system. The main problem in this research is: a combination of production planning and control the supply chain despite the limitations in the company capacity and constraint on investment and possibility of market demand, considering collection centers and recycling system check whether despite the constraint investment, setting up and establishment of collection and recycling center to what extent can (in the long term or even short-term) optimize the production costs. Therefore the presented study is a search for optimizing the production process along the supply chain control objectives with the feasibility of setting up recycling centers to reduce the prime cost, and increasing the profitability and ultimately increase customer satisfaction.

The main assumptions of the mathematical model include:
1- Parts supplier materials can be the new raw materials or recycled raw materials in the model.

2- The recovered items return to cycle with the same quality of raw materials.

3- The costs of transportation between the various stages of chain are different and independent to the amount of ordering.

4- If possible, collected materials from the customers are recycled and returned to the cycle, otherwise they are sent to scrapping center.

In the future, after introducing the variables, parameters, and indexes, the mathematical problem with the constraints are introduced.

\section{Mathematical proposed model}

Indexes are presented at the table number 1 , in Table 2 the decision variables used in the model has been stated with the symbol and the relevant definitions; and in Table 3 parameters have been introduced.

Table 1. symbols and definition of used indexes in the model

\begin{tabular}{cc}
\hline symbol & definition \\
\hline $\mathrm{p} \in\{1,2, \ldots, \mathrm{P}\}$ & Collection of factory products \\
\hline $\mathrm{k} \in\{1,2, \ldots, \mathrm{K}\}$ & Set of manufacturers(factories) \\
\hline $\mathrm{i} \in\{1,2, \ldots, \mathrm{I}\}$ & set of customers \\
\hline $\mathrm{c} \in\{1,2, \ldots, \mathrm{C}\}$ & Set of parts suppliers \\
\hline $\mathrm{v} \in\{1,2, \ldots, \mathrm{V}\}$ & Collection of raw materials \\
\hline $\mathrm{r} \in\{1,2, \ldots, \mathrm{R}\}$ & Set of raw materials suppliers \\
\hline $\mathrm{s} \in\{1,2, \ldots, \mathrm{S}\}$ & Set of collection centers \\
\hline $\mathrm{h} \in\{1,2, \ldots, \mathrm{H}\}$ & Set of disassembling centers \\
\hline $\mathrm{a} \in\{1,2, \ldots, \mathrm{A}\}$ & Set of recycling centers \\
\hline $\mathrm{w} \in\{1,2, \ldots, \mathrm{W}\}$ & Set of scrapping centers \\
\hline $\mathrm{d} \in\{1,2, \ldots, \mathrm{D}\}$ & Set of periods
\end{tabular}


Table 2. symbol and model decision variables definition

\begin{tabular}{cc}
\hline symbol & definition \\
\hline$Q S_{s, v, r, t}$ & The amount of $\mathbf{r}$ sent raw material from $\mathbf{s}$ to $\mathbf{v}$ in period $\mathbf{t}$ \\
\hline$Q W_{w, v, r, t}$ & The amount of $\mathbf{r}$ sent recycled material from $\mathbf{w}$ to $\mathbf{v}$ in period $\mathbf{t}$ \\
\hline$Q V_{v, k, c, t}$ & The amount of part $\mathbf{c}$ sent from $\mathbf{v}$ to $\mathbf{k}$ \\
\hline$Q I_{i, h, p, t}$ & The number of collected $\mathbf{p}$ product from customer $\mathbf{i}$ in $\mathbf{h}$ center in $\mathbf{t}$ period \\
\hline$Q H_{h, w, p, t}$ & Amount of sent $\mathbf{p}$ product from $\mathbf{h}$ collection center to $\mathbf{w}$ recycling in period $\mathbf{t}$ \\
\hline$Q k_{k, i, p, t}$ & Amount of sent $\mathbf{p}$ product from $\mathbf{k}$ manufacturer to $\mathbf{i}$ customer in period $\mathbf{t}$ \\
\hline$Z H_{h}$ & If the collection center $\mathbf{h}$ is created and set up, equates 1 otherwise zero \\
\hline$Z W_{w}$ & If the recycling center $\mathbf{w}$ is created and set up it, equates 1 otherwise zero \\
\hline$Z D_{d}$ & If scrapping center $\mathbf{d}$ is created and set up, equates 1 otherwise zero \\
\hline$X K_{p, k, t}$ & Amount of produced product $\mathbf{p}$ by manufacture $\mathbf{k}$ in period $\mathbf{t}$ \\
\hline$X V_{c, v, t}$ & The main produced part $\mathbf{c}$ by supplier $\mathbf{c}$ in period $\mathbf{t}$ \\
\hline$X S_{r, s, t}$ & The amount of supplied raw material $\mathbf{r}$ by supplier $\mathbf{s}$ in period $\mathbf{t}$ \\
\hline$X W_{r, p, w, t}$ & The amount of recycled raw material $\mathbf{r}$ by recycling center $\mathbf{w}$ in period $\mathbf{t}$ \\
\hline$I S_{s, r, t}$ & Inventory of raw material $\mathbf{r}$ in supplier warehouse $\mathbf{s}$ in period $\mathbf{t}$ \\
\hline$I V_{v, c, t}$ & Inventory of part $\mathbf{c}$ in supplier warehouse $\mathbf{v}$ in period $\mathbf{t}$ \\
\hline$I K_{k, p, t}$ & Inventory of product $\mathbf{p}$ in manufacture warehouse $\mathbf{k}$ in period $\mathbf{t}$ \\
\hline$I W_{w, r, t}$ & Inventory of raw material $\mathbf{r}$ in recycling center warehouse $\mathbf{k}$ in period $\mathbf{t}$ \\
\hline$I H_{h, p, t}$ & Inventory of product $\mathbf{p}$ in collection center warehouse $\mathbf{h}$ in period $\mathbf{t}$ \\
\hline
\end{tabular}

Table 3. used parameters definitions and symbol in model

\begin{tabular}{cc}
\hline symbol & definition \\
\hline$R T C_{k, c, p}$ & The number of used part $\mathbf{c}$ in manufacture $\mathbf{k}$ for manufacturing product $\mathbf{p}$ \\
\hline$R T R_{v, r, c}$ & Using rate of supplier $\mathbf{v}$ from raw material $\mathbf{r}$ to manufacture part $\mathbf{c}$ \\
\hline$R T D_{p, w, t}$ & The rate of scrapping product $\mathbf{p}$ in recycling center $\mathbf{w}$ in period $\mathbf{t}$ \\
\hline$R T W_{p, h, t}$ & The rate of recycling product $\mathbf{p}$ in collection center $\mathbf{h}$ in period $\mathbf{t}$ \\
\hline$C A P_{k, p}$ & The capacity of manufacturer $\mathbf{k}$ to produce product $\mathbf{p}$ \\
\hline$C A C_{v, c}$ & The capacity of supplier $\mathbf{p}$ to supply part $\mathbf{c}$ \\
\hline$C A R_{s, r}$ & The capacity of raw material $\mathbf{s}$ to produce raw material $\mathbf{r}$ \\
\hline$C A D_{d, p}$ & The capacity of scrapping center $\mathbf{d}$ to scrap product $\mathbf{p}$ \\
\hline$B u f_{h, p}$ & The capacity of collection center $\mathbf{h}$ to warehouse product $\mathbf{p}$ \\
\hline$C O P_{k, p, t}$ & The cost of making product $\mathbf{p}$ by factory $\mathbf{k}$ in period $\mathbf{t}$ \\
\hline$C O C_{v, c, t}$ & The cost of manufacture part $\mathbf{c}$ by supplier $\mathbf{v}$ in period $\mathbf{t}$ \\
\hline
\end{tabular}


Table 4. used parameters definitions and symbol in model (continued)

\begin{tabular}{|c|c|}
\hline$C O D_{p, d, t}$ & The cost of scrapping $\mathbf{p}$ product by $\mathbf{d}$ scrapping centres \\
\hline$C O R_{s, r, t}$ & The cost of providing $\mathbf{r}$ raw materials by s suppliers in period $\mathbf{t}$ \\
\hline$C B P_{k, p}$ & $\begin{array}{l}\text { The cost of warehousing a unit of } \mathbf{p} \text { product in warehouse } \\
\text { manufacturer } \mathbf{k}\end{array}$ \\
\hline$C B C_{v, c}$ & The cost of warehousing a unit $\mathbf{p}$ part warehouse manufacturer $\mathbf{v}$ \\
\hline$C B R S_{s, r}$ & $\begin{array}{l}\text { The cost of warehousing one unit } \mathbf{r} \text { raw materials in supplier } \\
\text { warehouse of } \mathbf{s} \text { raw materials }\end{array}$ \\
\hline$C B R W_{w, r}$ & The cost of one unit $\mathbf{r}$ raw materials in $\mathbf{w}$ recycling center warehouse \\
\hline$C T S_{s, v, r}$ & $\begin{array}{l}\text { The cost of purchasing, ordering, and transporting } \mathbf{r} \text { raw material } \\
\text { from } \mathbf{s} \text { suppliers to parts supplier }\end{array}$ \\
\hline$C T W_{w, v, r}$ & $\begin{array}{l}\text { The cost of purchasing, ordering, and transporting } \mathbf{r} \text { raw materials } \\
\text { from } \mathbf{w} \text { recycling to center } \mathbf{v} \text { supplier }\end{array}$ \\
\hline$C T V_{v, k, c}$ & $\begin{array}{l}\text { The cost of purchasing, ordering, and transporting } \mathbf{c} \text { part } \\
\text { transportation from } \mathbf{v} \text { supplier to } \mathbf{k} \text { manufacture }\end{array}$ \\
\hline$C T K_{k, i, p}$ & $\begin{array}{l}\text { The cost of purchasing, ordering, and transporting } \mathbf{p} \text { product from } \\
\text { manufacture } \mathbf{k} \text { to customer } \mathbf{i}\end{array}$ \\
\hline$C T H_{h, w, p}$ & $\begin{array}{l}\text { The cost of purchasing, ordering, and transporting product } \mathbf{p} \text { from } \\
\text { collection center } \mathbf{h} \text { to recycling center } \mathbf{w}\end{array}$ \\
\hline$C T I_{i, h, p}$ & $\begin{array}{l}\text { The cost of purchasing and collecting on product } \mathbf{p} \text { from customer } \mathbf{i} \\
\text { to collection center } \mathbf{h}\end{array}$ \\
\hline $\mathrm{CEH}_{h}$ & The cost of establishing and setting up $\mathbf{h}$ collection center \\
\hline$C E W_{w}$ & $\begin{array}{l}\text { The cost of establishing and setting up disassembly and recycling } \\
\text { center } \mathbf{w}\end{array}$ \\
\hline$C E D_{d}$ & The cost of establishing and setting up collection center $\mathbf{h}$ \\
\hline Bud & The amount of allocated investment \\
\hline$D_{i, p, t}$ & $\begin{array}{l}\text { The amount of potential demand for product } \mathbf{p} \text { by customer } \mathbf{i} \text { in } \\
\text { period } \mathbf{t}\end{array}$ \\
\hline
\end{tabular}

In this section formulating mathematical optimization model is presented. The supply chain liner model is a planning for different products in several stages considering the collecting, recycling, and scrapping centers.

The final form of the mathematical planning model which is presented in the study is:

$$
\mathrm{MIN} \mathrm{z}=\mathrm{Z}_{1}+\mathrm{Z}_{2}+\mathrm{Z}_{3}+\mathrm{Z}_{4}+\mathrm{Z}_{5}
$$

The model has four sets of constraints, and the expenses in the model include creating and setting up the recycle centres, production costs, the expenses of collecting recycle and scrapping centres, warehousing costs, and ordering and transportation expenses which are presented in (2) to (6) equations in detail.

$$
\mathrm{Z}_{1}=\sum_{\mathrm{h}=1}^{\mathrm{H}} \mathrm{ZH}_{\mathrm{h}} \cdot \mathrm{CEH}_{\mathrm{h}}+
$$
$\sum_{\mathrm{w}=1}^{\mathrm{W}} \mathrm{ZW}_{\mathrm{w}} \cdot \mathrm{CEW}_{\mathrm{w}}+\sum_{\mathrm{d}=1}^{\mathrm{D}} \mathrm{ZD}_{\mathrm{d}} \cdot \mathrm{CED}_{\mathrm{d}}$

(2)

The equation (3) is stated for calculating the expenses of setting up collecting, recycling, and scrapping centres in the case that if construction variables for each system equate (1), its setting up expenses are mentioned in the model

$$
\begin{aligned}
Z_{2}=\sum_{\mathrm{t}=1}^{\mathrm{T}} \sum_{\mathrm{k}=1}^{\mathrm{K}} \sum_{\mathrm{p}=1}^{\mathrm{P}} \mathrm{XK}_{\mathrm{p}, \mathrm{k}, \mathrm{t}} \cdot \mathrm{COP}_{\mathrm{k}, \mathrm{p}, \mathrm{t}} \\
+\sum_{\mathrm{t}=1}^{\mathrm{T}} \sum_{\mathrm{v}=1}^{\mathrm{V}} \sum_{\mathrm{c}=1}^{\mathrm{C}} \mathrm{XV}_{\mathrm{c}, \mathrm{v}, \mathrm{t}} \cdot \mathrm{COC}_{\mathrm{v}, \mathrm{c}, \mathrm{t}} \\
+\sum_{\mathrm{t}=1}^{\mathrm{S}} \sum_{\mathrm{s}=1}^{\mathrm{R}} \sum_{\mathrm{r}=1}^{\mathrm{COR}_{\mathrm{s}, \mathrm{r}, \mathrm{t}} \cdot \mathrm{XS}_{\mathrm{r}, \mathrm{s}, \mathrm{t}}}
\end{aligned}
$$


(3)

Equation (4) represents sum of the expenses of total production. The first term specifies the relation cost of all $\mathrm{P}$ goods in $\mathrm{K}$ factories with respect to the manufacture of any product; in the second term of above relationship, the producing cost of $C$ parts is measured by the suppliers according to the amount of each part. In the third term of relationship the total cost of raw materials for the suppliers is shown with regard to the supply of $\mathbf{r}$ raw materials. Generally the cost of production is considered in three levels of supplying raw materials, manufacturing components, and producing final good.

$$
\begin{aligned}
& \mathrm{Z}_{3} \sum_{\mathrm{t}=1}^{\mathrm{T}} \sum_{\mathrm{w}=1}^{\mathrm{W}} \sum_{\mathrm{r}=1}^{\mathrm{R}} \sum_{\mathrm{p}=1}^{\mathrm{P}}\left(\mathrm{COW}_{\mathrm{w}, \mathrm{r}, \mathrm{p}, \mathrm{t}}\right. \\
& \left.+\mathrm{ZA}_{\mathrm{a}, \mathrm{p}} \mathrm{COPA}_{\mathrm{a}, \mathrm{p}}\right) \mathrm{X}_{\mathrm{w}, \mathrm{r}, \mathrm{p}, \mathrm{t}} \\
& +\sum_{\mathrm{t}=1}^{\mathrm{T}} \sum_{\mathrm{w}=1}^{\mathrm{W}} \sum_{\mathrm{h}=1}^{\mathrm{H}} \sum_{\mathrm{p}=1}^{\mathrm{P}} \operatorname{COD}_{\mathrm{p}, \mathrm{d}, \mathrm{t}} \cdot \mathrm{RTD}_{\mathrm{p}, \mathrm{w}, \mathrm{t}} \cdot \mathrm{QH}_{\mathrm{h}, \mathrm{w}, \mathrm{p}, \mathrm{t}}
\end{aligned}
$$

In equation (5), total expenses of collection, recycling and disposal centers have been stated. In proportion to the amount of collected and recycled material or dismantled if necessary, costs have been calculated per unit.

$$
\begin{aligned}
& \mathrm{Z}_{4}=\sum_{\mathrm{t}=1}^{\mathrm{T}} \sum_{\mathrm{s}=1}^{\mathrm{S}} \sum_{\mathrm{r}=1}^{\mathrm{R}} \mathrm{IS}_{\mathrm{s}, \mathrm{r}, \mathrm{t}} \mathrm{CBRS}_{\mathrm{s}, \mathrm{t}}+ \\
& \sum_{\mathrm{t}=1}^{\mathrm{T}} \sum_{\mathrm{v}=1}^{\mathrm{V}} \sum_{\mathrm{c}=1}^{\mathrm{C}} \mathrm{IV}_{\mathrm{v}, \mathrm{c}, \mathrm{t}} \cdot \mathrm{CBC}_{\mathrm{v}, \mathrm{c}}+ \\
& \sum_{\mathrm{t}=1}^{\mathrm{T}} \sum_{\mathrm{k}=1}^{\mathrm{K}} \sum_{\mathrm{p}=1}^{\mathrm{P}} \mathrm{IK}_{\mathrm{k}, \mathrm{p}, \mathrm{t}} \cdot \mathrm{CBP}_{\mathrm{k}, \mathrm{p}}+ \\
& \sum_{\mathrm{t}=1}^{\mathrm{T}} \sum_{\mathrm{w}=1}^{\mathrm{W}} \sum_{\mathrm{r}=1}^{\mathrm{R}} \mathrm{IW}_{\mathrm{w}, \mathrm{r}, \mathrm{t}} \cdot \mathrm{CBRW}_{\mathrm{w}, \mathrm{r}}+ \\
& \sum_{\mathrm{t}=1}^{\mathrm{T}} \sum_{\mathrm{h}=1}^{\mathrm{H}} \sum_{\mathrm{p}=1}^{\mathrm{P}} \mathrm{IH}_{\mathrm{h}, \mathrm{p}, \mathrm{t}} \cdot \mathrm{CBPH}_{\mathrm{h}, \mathrm{p}}
\end{aligned}
$$

In the above equation, all warehousing costs due to the amount of raw materials, parts made ready to deliver, and produced goods in related factories is considered at various part of the model.

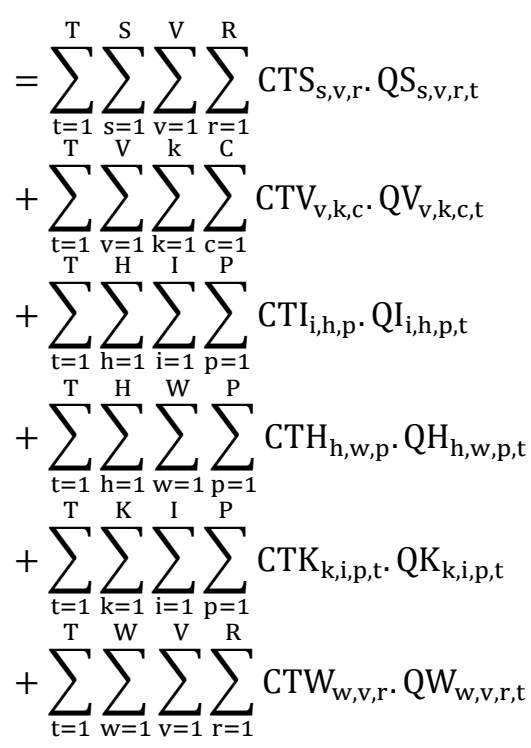

(6)

According to the model assumptions, all costs related to the transfer order and also cost order should exist in the model. The costs have been calculated in relationship number 7 . According to various parameters related to the order and transportation, these costs are calculated for preparation raw material centres, manufacturing parts, production of different goods and transfered to recycling and scrapping centers.Considered limits are given for optimization model according to assumptions and features of the model in equations (7) to (17).

$\sum_{\mathrm{t}=1}^{\mathrm{T}} \sum_{\mathrm{k}=1}^{\mathrm{K}} \sum_{\mathrm{p}=1}^{\mathrm{P}} \mathrm{IK}_{\mathrm{k}, \mathrm{p}, \mathrm{t}} \geq \sum_{\mathrm{t}=1}^{\mathrm{T}} \sum_{\mathrm{i}=1}^{\mathrm{I}} \sum_{\mathrm{p}=1}^{\mathrm{P}} \mathrm{D}_{\mathrm{i}, \mathrm{p}, \mathrm{t}}$

$\sum_{\mathrm{t}=1}^{\mathrm{T}} \sum_{\mathrm{v}=1}^{\mathrm{V}} \mathrm{IV}_{\mathrm{v}, \mathrm{c}, \mathrm{t}} \geq \sum_{\mathrm{t}=1}^{\mathrm{T}} \sum_{\mathrm{k}=1}^{\mathrm{K}} \sum_{\mathrm{p}=1}^{\mathrm{P}} \mathrm{RTC}_{\mathrm{k}, \mathrm{c}, \mathrm{p}} \cdot \mathrm{XK}_{\mathrm{p}, \mathrm{k}, \mathrm{t}} \forall \mathrm{c} \in \mathrm{C}$

$$
\begin{aligned}
\sum_{\mathrm{t}=1}^{\mathrm{T}} \sum_{\mathrm{w}=1}^{\mathrm{W}} \sum_{\mathrm{r}=1}^{\mathrm{R}} \mathrm{IW}_{\mathrm{w}, \mathrm{r}, \mathrm{t}} & +\sum_{\mathrm{t}=1}^{\mathrm{T}} \sum_{\mathrm{S}=1}^{\mathrm{S}} \sum_{\mathrm{r}=1}^{\mathrm{R}} \mathrm{IS}_{\mathrm{s}, \mathrm{r}, \mathrm{t}} \\
& \geq \sum_{\mathrm{t}=1}^{\mathrm{T}} \sum_{\mathrm{v}=1}^{\mathrm{V}} \sum_{\mathrm{c}=1}^{\mathrm{C}} \sum_{\mathrm{c}=1}^{\mathrm{C}} \mathrm{RTR}_{\mathrm{v}, \mathrm{r}, \mathrm{t}} \cdot \mathrm{XV}_{\mathrm{c}, \mathrm{v}, \mathrm{t}}
\end{aligned}
$$

Equations (7), (8) and (9) are stated to apply balance inventories with the demands, these relations limit that the minimum amount 
of raw materials, parts inventory and inventory of manufactured goods must be more than market demand. Demand for $\mathbf{r}$ raw material fulfilled by way of recycling centres inventory and $\mathrm{r}$ raw materials providers.

$$
\begin{aligned}
& \sum_{\mathrm{k}=1}^{\mathrm{K}} \sum_{\mathrm{p}=1}^{\mathrm{P}} \mathrm{XK}_{\mathrm{k}, \mathrm{p}, \mathrm{t}} \leq \sum_{\mathrm{i}=1}^{\mathrm{I}} \sum_{\mathrm{p}=1}^{\mathrm{P}} \mathrm{CAP}_{\mathrm{k}, \mathrm{p}, \mathrm{t}} \quad \forall \mathrm{t} \in \mathrm{T} \\
& \sum_{\mathrm{c}=1}^{\mathrm{C}} \sum_{\mathrm{v}=1}^{\mathrm{V}} \mathrm{XV}_{\mathrm{c}, \mathrm{v}, \mathrm{t}} \leq \sum_{\mathrm{v}=1}^{\mathrm{V}} \sum_{\mathrm{c}=1}^{\mathrm{C}} \mathrm{CAC}_{\mathrm{v}, \mathrm{c}, \mathrm{t}} \quad \forall \mathrm{t} \in \mathrm{T} \\
& \sum_{\mathrm{s}=1}^{\mathrm{S}} \sum_{\mathrm{r}=1}^{\mathrm{R}} \mathrm{XS}_{\mathrm{r}, \mathrm{s}, \mathrm{t}} \leq \sum_{\mathrm{s}=1}^{\mathrm{S}} \sum_{\mathrm{r}=1}^{\mathrm{R}} \mathrm{CAR}_{\mathrm{s}, \mathrm{r}, \mathrm{t}} \quad \forall \mathrm{t} \in \mathrm{T} \\
& \sum_{\mathrm{h}=1}^{\mathrm{H}} \sum_{\mathrm{p}=1}^{\mathrm{P}} \mathrm{RTW}_{\mathrm{p}, \mathrm{h}, \mathrm{t}} \cdot \mathrm{D}_{\mathrm{i}, \mathrm{p}, \mathrm{t}} \leq \sum_{\mathrm{h}=1}^{\mathrm{H}} \sum_{\mathrm{p}=1}^{\mathrm{P}} \mathrm{Buf}_{\mathrm{h}, \mathrm{p}, \mathrm{t}} \quad \forall \mathrm{t} \\
& \sum_{\mathrm{w}=1}^{\mathrm{W}} \sum_{\mathrm{h}=1}^{\mathrm{H}} \sum_{\mathrm{p}=1}^{\mathrm{P}} \mathrm{RTD}_{\mathrm{p}, \mathrm{w}, \mathrm{t}} \cdot \mathrm{QH} \mathrm{H}_{\mathrm{h}, \mathrm{w}, \mathrm{p}, \mathrm{t}}^{\mathrm{T}} \\
& \sum_{\mathrm{s}=1}^{\mathrm{S}} \sum_{\mathrm{r}=1}^{\mathrm{R}} \mathrm{XS}_{\mathrm{r}, \mathrm{s}, \mathrm{t}} \leq \sum_{\mathrm{s}=1}^{\mathrm{P}} \sum_{\mathrm{r}=1}^{\mathrm{P}} \sum_{\mathrm{p}=1}^{\mathrm{C}} \mathrm{CAD}_{\mathrm{d}, \mathrm{p}, \mathrm{t}}^{\mathrm{C}} \quad \forall \mathrm{t} \in \mathrm{T}
\end{aligned}
$$

Equations (10) to (15) indicate the restrictions in the capacity of various centers, for example in equation (10) the amount of producing the goods $\mathbf{P}$ in $\mathbf{k}$ factory is considered equal to the maximum capacity for its production. Also in raw material supplier centers, parts supplier, recycling and scrapping centers, the same restriction has been applied.

$$
\begin{aligned}
\sum_{\mathrm{h}=1}^{\mathrm{H}} \mathrm{ZH}_{\mathrm{h}} \cdot \mathrm{CEH}_{\mathrm{h}}+ & \sum_{\mathrm{w}=1}^{\mathrm{W}} \mathrm{ZW}_{\mathrm{w}} \cdot \mathrm{CEW}_{\mathrm{w}} \\
& +\sum_{\mathrm{d}=1}^{\mathrm{D}} \mathrm{ZD}_{\mathrm{d}} \cdot \mathrm{CED}_{\mathrm{d}} \leq \mathrm{Bud}
\end{aligned}
$$

The equation number (16), is considered to make a balance between setting up costs of collection centers, recycling and scrapping with the available investment.

$\mathrm{ZH}_{\mathrm{h}} \in\{0,1\} \forall \mathrm{h} \in \mathrm{H}$

$\mathrm{ZW}_{\mathrm{w}} \in\{0,1\} \forall \mathrm{w} \in \mathrm{W}$

$\mathrm{ZD}_{\mathrm{d}} \in\{0,1\} \forall \mathrm{d} \in \mathrm{D}$

$\mathrm{QS}_{\mathrm{s}, \mathrm{v}, \mathrm{r}, \mathrm{t}} \geq 0$, integer $\forall \mathrm{s} \in \mathrm{S}, \forall \mathrm{v} \in \mathrm{V}, \forall \mathrm{r} \in \mathrm{R}, \forall \mathrm{t}$ $\in \mathrm{T}$

$\mathrm{QW}_{\mathrm{w}, \mathrm{v}, \mathrm{r}, \mathrm{t}} \geq 0$, integer $\forall \mathrm{w} \in \mathrm{W}, \forall \mathrm{v} \in \mathrm{V}, \forall \mathrm{r}$ $\in \mathrm{R}, \forall \mathrm{t} \in \mathrm{T}$

$\mathrm{QV}_{\mathrm{v}, \mathrm{k}, \mathrm{c}, \mathrm{t}} \geq 0$, integer $\forall \mathrm{v} \in \mathrm{V}, \forall \mathrm{k} \in \mathrm{K}, \forall \mathrm{c} \in \mathrm{C}, \forall \mathrm{t}$ $\in \mathrm{T}$

$\mathrm{QI}_{\mathrm{i}, \mathrm{h}, \mathrm{p}, \mathrm{t}} \geq 0$, integer $\forall \mathrm{i} \in \mathrm{V}, \forall \mathrm{h} \in \mathrm{H}, \forall \mathrm{p} \in \mathrm{P}, \forall \mathrm{t}$ $\in \mathrm{T}$

$\mathrm{QH}_{\mathrm{h}, \mathrm{w}, \mathrm{p}, \mathrm{t}} \geq 0$, integer $\forall \mathrm{w} \in \mathrm{W}, \forall \mathrm{h} \in \mathrm{H}, \forall \mathrm{p}$ $\in \mathrm{P}, \forall \mathrm{t} \in \mathrm{T}$

$\mathrm{Qk}_{\mathrm{k}, \mathrm{i}, \mathrm{p}, \mathrm{t}} \geq 0$, integer $\forall \mathrm{k} \in \mathrm{K}, \forall \mathrm{i} \in \mathrm{I}, \forall \mathrm{p} \in \mathrm{P}, \forall \mathrm{t}$ $\in \mathrm{T}$

$\mathrm{XK}_{\mathrm{p}, \mathrm{k}, \mathrm{t}} \geq 0$, integer $\forall \mathrm{k} \in \mathrm{K}, \forall \mathrm{p} \in \mathrm{P}, \forall \mathrm{t} \in \mathrm{T}$

$\mathrm{XV}_{\mathrm{c}, \mathrm{v}, \mathrm{t}} \geq 0$, integer $\forall \mathrm{v} \in \mathrm{V}, \forall \mathrm{c} \in \mathrm{C}, \forall \mathrm{t} \in \mathrm{T}$

$\mathrm{XS}_{\mathrm{r}, \mathrm{s}, \mathrm{t}} \geq 0$, integer $\forall \mathrm{r} \in \mathrm{R}, \forall \mathrm{s} \in \mathrm{S}, \forall \mathrm{t} \in \mathrm{T}$

$\mathrm{XW}_{\mathrm{r}, \mathrm{p}, \mathrm{w}, \mathrm{t}} \geq 0$, integer $\forall \mathrm{r} \in \mathrm{R}, \forall \mathrm{p} \in \mathrm{P}, \forall \mathrm{w} \in \mathrm{W}, \forall \mathrm{t}$ $\in \mathrm{T}$

$\mathrm{IS}_{\mathrm{s}, \mathrm{r}, \mathrm{t}} \geq 0$, integer $\forall \mathrm{r} \in \mathrm{R}, \forall \mathrm{s} \in \mathrm{S}, \forall \mathrm{t} \in \mathrm{T}$

$\mathrm{IV}_{\mathrm{v}, \mathrm{c}, \mathrm{t}} \geq 0$, integer $\forall \mathrm{v} \in \mathrm{V}, \forall \mathrm{c} \in \mathrm{C}, \forall \mathrm{t} \in \mathrm{T}$

$\mathrm{IK}_{\mathrm{k}, \mathrm{p}, \mathrm{t}} \geq 0$, integer $\forall \mathrm{k} \in \mathrm{K}, \forall \mathrm{p} \in \mathrm{P}, \forall \mathrm{t} \in \mathrm{T}$

$\mathrm{IW}_{\mathrm{w}, \mathrm{r}, \mathrm{t}} \geq 0$, integer $\forall \mathrm{r} \in \mathrm{R}, \forall \mathrm{w} \in \mathrm{W}, \forall \mathrm{t} \in \mathrm{T}$

$\mathrm{IH}_{\mathrm{h}, \mathrm{p}, \mathrm{t}} \geq 0$, integer $\forall \mathrm{h} \in \mathrm{H}, \forall \mathrm{p} \in \mathrm{P}, \forall \mathrm{t} \in \mathrm{T}$

Also Equations (17) have been stated for restriction on model decision variables.

\section{Case Study}

To validate the presented model in this study, model structure was implemented in an industrial factory in the city of Ilam. The mentioned industrial company manufactures 
water pumps in different powers. Generally, pump component are electronic motor, couplings, bearing housing, pump blades, fluid mechanical and connectivity components. The required data for the model has been extracted from the factory and has been applied in the model (See tables 4, 5 and 6). In the first stage, model was optimized without considering the collection and recycling centres, and different values were obtained for the problem variables. In the second stage, the recycling centres were also added to the model, and since actual data such as start-up costs and the expenses of collecting and recycling were not available, an estimate of these costs extracted from experts in this filed were considered in the model, and results were resolved and implemented with LINGO software version 11.0, and was shown that the total cost of the system, considering the cost of setting up recycling centres increased over a period of 12 months but with the increasing range of simulation to 48 months, it was found that not only the investment costs in order to set up recycling centres were returned, but also the costs of producing each water pump unit were totally increased, this reducing cost was obtained because of created balance between using recycling raw materials rather than new raw materials, while only one consumer is considered to the output of recycling centre. So by increasing factories which have the possibility of using the recycling centres, reducing the total cost is predicted for the system. Due to the high output of the software, some part of it is shown in Table 7.

Table 4. indexes of case study

\begin{tabular}{llll}
\hline The cost of setting up recycling and scrapping centre & CEW & $\$ 150,000$ \\
\hline Total investment & BUD & $\$ 170,000$ \\
\hline Product number & $\mathrm{p}$ & 1 \\
\hline Number of parts & $\mathrm{C}$ & 4 \\
\hline Number of raw materials & $\mathrm{r}$ & 3 \\
\hline Number of factories & $\mathrm{k}$ & 1 \\
\hline Number of parts supplier & $\mathrm{v}$ & 1 \\
\hline Number of raw material suppliers & $\mathrm{s}$ & 1 \\
\hline Period & $\mathrm{t}$ & 12 \\
\hline Number of recycling and scrapping center & $\mathrm{W}$ & 1 \\
\hline Number of customer & $\mathrm{i}$ & 10 \\
\hline
\end{tabular}


Table 5. case study parameters

\begin{tabular}{|c|c|c|c|c|c|c|c|c|c|c|c|c|}
\hline $\mathbf{t}$ & 1 & 2 & 3 & 4 & 5 & 6 & 7 & 8 & 9 & 10 & 11 & 12 \\
\hline $\operatorname{COP}(t)$ & 50 & 50 & 50 & 50 & 50 & 50 & 50 & 50 & 50 & 50 & 50 & 50 \\
\hline $\operatorname{CBP}(t)$ & 1 & 1 & 1 & 1 & 1 & 1 & 1 & 1 & 1 & 1 & 1 & 1 \\
\hline $\mathbf{C A P}(t)$ & 3 & 3 & 3 & 3 & 3 & 3 & 3 & 3 & 3 & 3 & 3 & 3 \\
\hline $\mathbf{t}$ & 1 & 2 & 3 & 4 & 5 & 6 & 7 & 8 & 9 & 10 & 11 & 12 \\
\hline $\operatorname{COC}(\mathbf{c} 1, t)$ & 5 & 5 & 5 & 5 & 5 & 5 & 5 & 5 & 5 & 5 & 5 & 5 \\
\hline $\operatorname{COC}(\mathbf{c} 2, t)$ & 3 & 3 & 3 & 3 & 3 & 3 & 3 & 3 & 3 & 3 & 3 & 3 \\
\hline $\operatorname{COC}(\mathbf{c} 3, t)$ & 2 & 2 & 2 & 2 & 2 & 2 & 2 & 2 & 2 & 2 & 2 & 2 \\
\hline $\operatorname{COC}(\mathbf{c} 4, t)$ & 4 & 4 & 4 & 4 & 4 & 4 & 4 & 4 & 4 & 4 & 4 & 4 \\
\hline $\mathbf{t}$ & 1 & 2 & 3 & 4 & 5 & 6 & 7 & 8 & 9 & 10 & 11 & 12 \\
\hline $\mathrm{CBC}(\mathbf{c 1 , t})$ & 1 & 1 & 1 & 1 & 1 & 1 & 1 & 1 & 1 & 1 & 1 & 1 \\
\hline $\mathrm{CBC}(\mathbf{c} 2, \mathrm{t})$ & 0.5 & 0.5 & 0.5 & 0.5 & 0.5 & 0.5 & 0.5 & 0.5 & 0.5 & 0.5 & 0.5 & 0.5 \\
\hline $\mathrm{CBC}(\mathbf{c} 3, \mathrm{t})$ & 0.5 & 0.5 & 0.5 & 0.5 & 0.5 & 0.5 & 0.5 & 0.5 & 0.5 & 0.5 & 0.5 & 0.5 \\
\hline $\mathrm{CBC}(\mathbf{c 4 , t})$ & 0.5 & 0.5 & 0.5 & 0.5 & 0.5 & 0.5 & 0.5 & 0.5 & 0.5 & 0.5 & 0.5 & 0.5 \\
\hline $\mathbf{t}$ & 1 & 2 & 3 & 4 & 5 & 6 & 7 & 8 & 9 & 10 & 11 & 12 \\
\hline $\mathrm{CAC}(\mathbf{c} 1, \mathrm{t})$ & 4 & 4 & 4 & 4 & 4 & 4 & 4 & 4 & 4 & 4 & 4 & 4 \\
\hline $\mathrm{CAC}(\mathrm{c} 2, \mathrm{t})$ & 5 & 5 & 5 & 5 & 5 & 5 & 5 & 5 & 5 & 5 & 5 & 5 \\
\hline $\mathrm{CAC}(\mathbf{c} 3, \mathrm{t})$ & 3 & 3 & 3 & 3 & 3 & 3 & 3 & 3 & 3 & 3 & 3 & 3 \\
\hline $\mathrm{CAC}(\mathrm{c} 4, \mathrm{t})$ & 4 & 4 & 4 & 4 & 4 & 4 & 4 & 4 & 4 & 4 & 4 & 4 \\
\hline$t$ & 1 & 2 & 3 & 4 & 5 & 6 & 7 & 8 & 9 & 10 & 11 & 12 \\
\hline RTC $(\mathbf{c 1 , t})$ & 0.2 & 0.2 & 0.2 & 0.2 & 0.2 & 0.2 & 0.2 & 0.2 & 0.2 & 0.2 & 0.2 & 0.2 \\
\hline RTC $(\mathbf{c} 2, t)$ & 0.35 & 0.35 & 0.35 & 0.35 & 0.35 & 0.35 & 0.35 & 0.35 & 0.35 & 0.35 & 0.35 & 0.35 \\
\hline RTC $(\mathbf{c} 3, t)$ & 0.2 & 0.2 & 0.2 & 0.2 & 0.2 & 0.2 & 0.2 & 0.2 & 0.2 & 0.2 & 0.2 & 0.2 \\
\hline RTC $(\mathbf{c} 4, t)$ & 0.25 & 0.25 & 0.25 & 0.25 & 0.25 & 0.25 & 0.25 & 0.25 & 0.25 & 0.25 & 0.25 & 0.25 \\
\hline $\mathbf{t}$ & 1 & 2 & 3 & 4 & 5 & 6 & 7 & 8 & 9 & 10 & 11 & 12 \\
\hline $\operatorname{COR}(\mathbf{r} 1, t)$ & 0.5 & 0.5 & 0.5 & 0.5 & 0.5 & 0.5 & 0.5 & 0.5 & 0.5 & 0.5 & 0.5 & 0.5 \\
\hline $\operatorname{COR}(\mathbf{r} 2, \mathrm{t})$ & 0.7 & 0.7 & 0.7 & 0.7 & 0.7 & 0.7 & 0.7 & 0.7 & 0.7 & 0.7 & 0.7 & 0.7 \\
\hline $\operatorname{COR}(r 3, t)$ & 1.1 & 1.1 & 1.1 & 1.1 & 1.1 & 1.1 & 1.1 & 1.1 & 1.1 & 1.1 & 1.1 & 1.1 \\
\hline $\mathbf{t}$ & 1 & 2 & 3 & 4 & 5 & 6 & 7 & 8 & 9 & 10 & 11 & 12 \\
\hline $\operatorname{COW}(\mathbf{r} 1, \mathbf{t})$ & 1.0 & 1.0 & 1.0 & 1.0 & 1.0 & 1.0 & 1.0 & 1.0 & 1.0 & 1.0 & 1.0 & 1.0 \\
\hline $\operatorname{COW}(r 2, t)$ & 1.5 & 1.5 & 1.5 & 1.5 & 1.5 & 1.5 & 1.5 & 1.5 & 1.5 & 1.5 & 1.5 & 1.5 \\
\hline $\operatorname{COW}(r 3, t)$ & 2.5 & 2.5 & 2.5 & 2.5 & 2.5 & 2.5 & 2.5 & 2.5 & 2.5 & 2.5 & 2.5 & 2.5 \\
\hline $\mathbf{t}$ & 1 & 2 & 3 & 4 & 5 & 6 & 7 & 8 & 9 & 10 & 11 & 12 \\
\hline CBRS(r1,t) & 1 & 1 & 1 & 1 & 1 & 1 & 1 & 1 & 1 & 1 & 1 & 1 \\
\hline CBRS(r2,t) & 1.5 & 1.5 & 1.5 & 1.5 & 1.5 & 1.5 & 1.5 & 1.5 & 1.5 & 1.5 & 1.5 & 1.5 \\
\hline CBRS(r3,t) & 2.5 & 2.5 & 2.5 & 2.5 & 2.5 & 2.5 & 2.5 & 2.5 & 2.5 & 2.5 & 2.5 & 2.5 \\
\hline
\end{tabular}


Table 6 . case study parameters

\begin{tabular}{|l|l|l|l|l|l|l|l|l|l|l|l|l|}
\hline t & $\mathbf{1}$ & $\mathbf{2}$ & $\mathbf{3}$ & $\mathbf{4}$ & $\mathbf{5}$ & $\mathbf{6}$ & $\mathbf{7}$ & $\mathbf{8}$ & $\mathbf{9}$ & $\mathbf{1 0}$ & $\mathbf{1 1}$ & $\mathbf{1 2}$ \\
\hline CBRW(r1,t) & 1 & 1 & 1 & 1 & 1 & 1 & 1 & 1 & 1 & 1 & 1 & 1 \\
\hline CBRW(r2,t) & 1.5 & 1.5 & 1.5 & 1.5 & 1.5 & 1.5 & 1.5 & 1.5 & 1.5 & 1.5 & 1.5 & 1.5 \\
\hline CBRW(r3,t) & 2.5 & 2.5 & 2.5 & 2.5 & 2.5 & 2.5 & 2.5 & 2.5 & 2.5 & 2.5 & 2.5 & 2.5 \\
\hline $\mathbf{t}$ & 1 & 2 & 3 & 4 & 5 & 6 & 7 & 8 & 9 & 10 & 11 & 12 \\
\hline RTR(r1,t) & 0.4 & 0.4 & 0.4 & 0.4 & 0.4 & 0.4 & 0.4 & 0.4 & 0.4 & 0.4 & 0.4 & 0.4 \\
\hline RTR(r2,t) & 0.35 & 0.35 & 0.35 & 0.35 & 0.35 & 0.35 & 0.35 & 0.35 & 0.35 & 0.35 & 0.35 & 0.35 \\
\hline RTR(r3,t) & 0.25 & 0.25 & 0.25 & 0.25 & 0.25 & 0.25 & 0.25 & 0.25 & 0.25 & 0.25 & 0.25 & 0.25 \\
\hline t & 1 & 2 & 3 & 4 & 5 & 6 & 7 & 8 & 9 & 10 & 11 & 12 \\
\hline CAR(r1,t) & 4 & 4 & 4 & 4 & 4 & 4 & 4 & 4 & 4 & 4 & 4 & 4 \\
\hline CAR(r2,t) & 3 & 3 & 3 & 3 & 3 & 3 & 3 & 3 & 3 & 3 & 3 & 3 \\
\hline CAR(r3,t) & 5 & 5 & 5 & 5 & 5 & 5 & 5 & 5 & 5 & 5 & 5 & 5 \\
\hline $\mathbf{t}$ & 1 & 2 & 3 & 4 & 5 & 6 & 7 & 8 & 9 & 10 & 11 & 12 \\
\hline D(i1,t) & 1 & 3 & 3 & 3 & 1 & 1 & 1 & 1 & 3 & 1 & 2 & 3 \\
\hline D(i2,t) & 3 & 4 & 2 & 2 & 2 & 1 & 2 & 3 & 1 & 4 & 3 & 1 \\
\hline D(i3,t) & 1 & 2 & 3 & 2 & 3 & 1 & 1 & 3 & 1 & 3 & 3 & 4 \\
\hline D(i4,t) & 4 & 2 & 2 & 2 & 4 & 2 & 4 & 3 & 1 & 2 & 4 & 3 \\
\hline D(i5,t) & 3 & 4 & 2 & 3 & 1 & 4 & 4 & 2 & 1 & 4 & 3 & 3 \\
\hline D(i6,t) & 4 & 3 & 2 & 3 & 2 & 3 & 1 & 4 & 3 & 4 & 3 & 2 \\
\hline D(i7,t) & 2 & 3 & 4 & 2 & 4 & 4 & 1 & 3 & 3 & 1 & 3 & 3 \\
\hline D(i8,t) & 1 & 2 & 3 & 1 & 3 & 4 & 2 & 2 & 4 & 3 & 3 & 3 \\
\hline D(i9,t) & 2 & 4 & 4 & 4 & 2 & 2 & 3 & 1 & 2 & 4 & 4 & 4 \\
\hline D(i10,t) & 1 & 2 & 2 & 4 & 3 & 2 & 2 & 3 & 2 & 2 & 2 & 3 \\
\hline
\end{tabular}

Table 7. part of model answer

\begin{tabular}{|ccc|}
\hline $\begin{array}{c}\text { Global optimal solution found. } \\
\text { Objective value: } \\
\text { Objective bound: }\end{array}$ & \multicolumn{2}{c|}{307.0000} \\
\hline Variable & Value & Reduced Cost \\
NT & 12.00000 & 0.000000 \\
NC & 4.000000 & 0.000000 \\
NR & 3.000000 & 0.000000 \\
NI & 10.00000 & 0.000000 \\
BUD & 170000.0 & 0.000000 \\
CEW & 150000.0 & 0.000000 \\
ZW( 1$)$ & 0.000000 & 150000.0 \\
COP( 1$)$ & 50.00000 & 0.000000 \\
COP( 2$)$ & 50.00000 & 0.000000 \\
COP(3) & 50.00000 & 0.000000 \\
\hline
\end{tabular}




\section{Conclusion}

In this study a comprehensive model was presented at the macro level for product planning and supply chain management that in addition to considering production constraints and the capacity of the company, investment restrictions, possibility of considering the recycling and scrapping centres were added to the model. Therefore, it is a model for optimization of product process beside the objectives of supply chain control with the feasibility of setting up recycling centres to reduce the costs of product and increase profitability, and finally leads to yu6increase customer satisfaction and productivity of the production system.

The main assumptions of the mathematical model include:

1- Parts supplier materials can be the new raw materials or recycled raw materials in the model.

2- The recovered items return to cycle with the same quality of raw materials.

3- The costs of transportation between the various stages of chain are different and independent to the amount of ordering.

4- If possible, collected materials from the customers are recycled and returned to the cycle, otherwise they are sent to scrapping center.

The objective function of the model includes optimizing (minimize) the costs of creating and setting up recycling centres, production costs, the costs of collection centers, recycling and scrapping, storage and transportation costs and the costs of orders. 11 restrictions were also included in this model. These limits will ensure that the minimum amount of raw materials inventory, parts inventory and inventory of manufactured goods must be more than market demands. Demands of raw materials are fulfilled through recycling centers and inventory and raw material suppliers. In other production restrictions the capacity of other centres is considered, For example, equation (10) shows that amount of producing the good $\mathbf{P}$ in $\mathbf{k}$ factory is equal to highest the intended capacity for that good, the same restriction is applied in the raw materials suppliers, parts suppliers, recycling and scrapping centres. To make a balance between the expenses of setting up collection centres, recycling and scrapping with the amount of available investment is also considered in appropriate restrictions. Continuously, to validate the presented model in this study it has been implemented in the water pump manufacturing company. In general, components of pumps, electric motors, couplings, bearing housing, pump blades, fluid mechanical and connecting components have been considered and research models was implemented and solved in LINGO software version 11.0

\section{REFERENCES}

Wang, R-C and Fang H-H. (2000). "Aggregate production planning with in a fuzzy environment. International Journal of Industrial Engineering - Theory", Applications and Practice, 7: 5-14.

Lai, Y.J and Hwang, C.L. (2011). "Lecture notes in economics and mathematical systems, fuzzy multiple objective decisions making. Spinger-Verlang", Great Britain.

Singhal, J. and Singhal, K. (2006). "Holt, Modigliani, Moth, and Simon's work and its role in the renaissance and evolution of operations management", Journal of Operations Management, 25, 300-309.

Techawiboonwong, A . and Yenradee, P. (2013). "Aggregate production planning with workforce transferring plan for multiple product types", Production Planning and Control, 14, 5: 447-458.

Feizabadi, Javad. "An Introductory to Supply Chain Management", Tadbir Journal; Issue No.131; March

Stedler and Kliger. Supply Chain Management and Advanced Planning. Translators: 
Asgari, Nasrin; Zanjirani, Reza.Termeh Pub. Tehran. First Print,9.

Mark, CH, (2013), "Product liability under the Consumer Protection Act, s. PWS publishing", Boston, MA.

Jones, A., (2012), "Analysis of Algorithms: An Active Learning Approach, g, pp. 513-528, Utilities Mathematical Publishing", Winnipeg, Canada.

Masud, A.S.M. and Hwang, C.L. (2011). "Aggregate production planning model and application of three objective decision methods", International Journal of Operations Research, 18: 741-752.

M Ghane, MJ Tarokh, Multi-objective design of fuzzy logic controller in supply chain, Journal of Industrial Engineering International 8 (1), 1-8 